\title{
COLOUR MASKS IN DIGITAL IMAGE ANALYSIS: A TECHNIQUE FOR MODAL ANALYSES OF QUARTZ SATURATED PLUTONIC ROCKS
}

\author{
BRENT A. ELLIOTT
}

\begin{abstract}
ELLIOTT, BRENT A. 1999. Colour masks in digital image analysis: a technique for modal analyses of quartz saturated plutonic rocks. Bulletin of the Geological Society of Finland, Number 71, Part 2, 233-241.

Mineral modes can be calculated quickly and accurately by using colour masks in scanned digital images of stained, quartz saturated plutonic rocks. The image analysis method for determining modal compositions is as accurate as manual point counting, and remarkably faster. A comparison of the manual point counting and pixel resolution methods, and a step by step procedure for calculating mineral modes in quartz saturated plutonic rocks are provided to make modal composition calculations fast, accurate, and efficient.
\end{abstract}

Key words: plutonic rocks, modal analysis, staining, image analysis, color masks, techniques

Brent A. Elliott: Department of Geology, P.O. Box 11, FIN-00014 University of Helsinki, Finland.

E-mail: brent.elliott@helsinki.fi

\section{INTRODUCTION}

Calculating modal compositions for coarsegrained granitic rocks is generally a long, time consuming process. Thin section point counting produces a wide range of error for mineral mode calculations. Manual point counting of stained, larger rock slabs, although more precise than thin section counting, is a long and tedious method. With the aid of graphic software, such as Corel Photo-Paint $7^{\mathrm{TM} 1}$, and a scanner, modal proportions of quartz and feldspars of stained coarsegrained granitic rocks can be determined more quickly and with a high degree of accuracy. After a coarse-grained granitic rock has been cut,

\footnotetext{
${ }^{1}$ Corel Photo-Paint is a trademark of Corel Corporation.
}

stained with sodium cobaltinitrite (III), and scanned as a photo image, the image can be reduced to the colour of pixels, and accurately analysed for mineral mode compositions based on the colour of stained minerals. The purpose of this paper is to outline the modal calculation procedure and discuss viability of its application.

\section{STAINING METHOD}

Samples are cut so that a relatively large surface area of the rock sample can be analysed. For example, a rock with an average grain size of $1.5 \mathrm{~cm}$ should have a cut surface area of at least $150 \mathrm{~cm}^{2}$. The cut surface is placed in hydrofluoric acid (60\%) for approximately 30 seconds. The surface 
is rinsed with water and placed in a solution of super-saturated sodium-cobaltinitrite (III) for approximately 30 seconds. The sample is rinsed and left to dry. The staining method should result in K-feldspar stained yellow or dark yellow, and plagioclase and quartz etched chalky white and grey, respectively. The staining method was originally developed by Gabriel and Cox (1929), and modified, or adapted, by Keith (1939), Chayes (1952), Rosenblum (1956), and Nold and Erickson (1976). Hayes and Klugman (1959) describe the use of this staining method on natural and artificial sands, and various other stains or augmentations to the staining process can be used to stain or identify plagioclase, orthopyroxene, clinopyroxene, and olivine (cf. Jackson \& Ross 1956 and Bailey \& Stevens 1960).

\section{ESTIMATION OF MODES BY COLOUR MASKING DIGITAL IMAGES}

\section{Scanning}

Samples should be carefully placed on a transparent sheet, on the scanning surface, to avoid scratching. Samples should be scanned at the highest possible pixel resolution and saved at a scale as close to $100 \%$ for the most accurate results. The images can then be saved as almost any image format (BMP, GIF, JPG, PCX, etc.) and easily accessed by Corel Photo-Paint $7^{\mathrm{TM}}$. After an image has been scanned and saved, it can be opened in Corel Photo-Paint $7^{\mathrm{TM}}$ by choosing "Open" from the "File" menu, and selecting the image file from the appropriate location (Fig. 1).

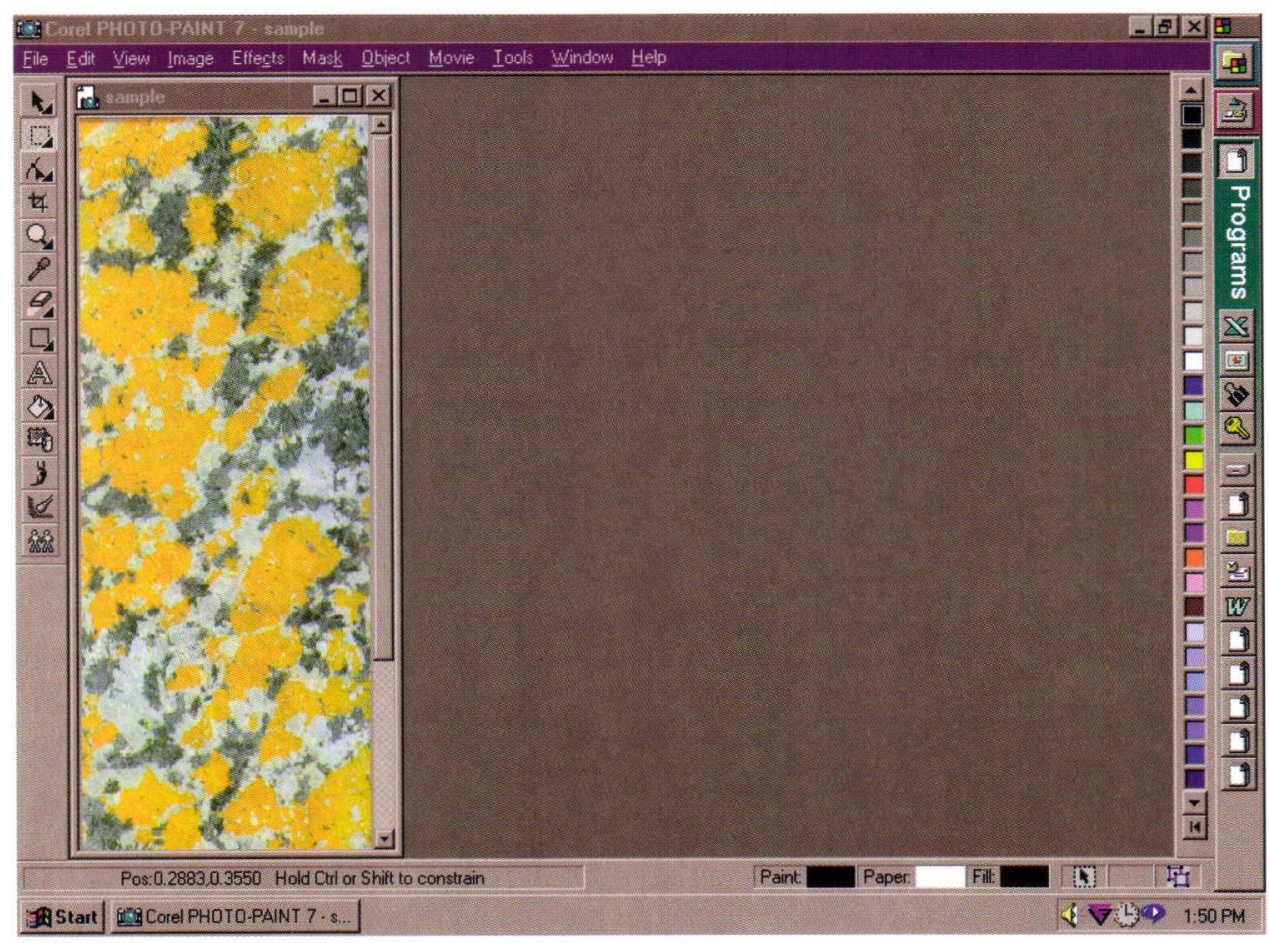

Fig. 1. A scanned image of a coarse-grained plutonic rock from the post-kinematic Petäjävesi pluton (see Nironen et al. in print) in Central Finland. The image was scanned at 600 dpi, saved as a *.PCX file and opened in Corel Photo-Paint 7 $7 \mathrm{TM}$. 


\section{Colour Masks and Determination of Mineral Modes}

A colour mask is a selected colour, or range of colours, throughout an image that can be preserved or edited. With a colour mask, the image can be converted to a binary image, one colour representing the selected mineral, the other colour representing the rest of the sample area. The determination of mineral modes by the colour masking procedure involves five steps outlined below:

Step \#1:

"Zoom in" on the mineral type you would like to make a colour mask of, using the magnifying glass icon (Fig. 2).
Step \#2:

Select a range of colours that represents that mineral (i.e. shades of yellow and dark yellow for alkali feldspar) using the eye dropper icon (Fig. 3). For a more accurate representation of the mineral mode in question, choose as many colour options as possible for the shades that represent that mineral (choose 30 shades of yellow rather than 10 shades of yellow, for example).

\section{Step \#3:}

Once a colour mask is created for a certain mineral, choose the overlay option "Greyscale" (Fig. 3), and press " $O K$ ".

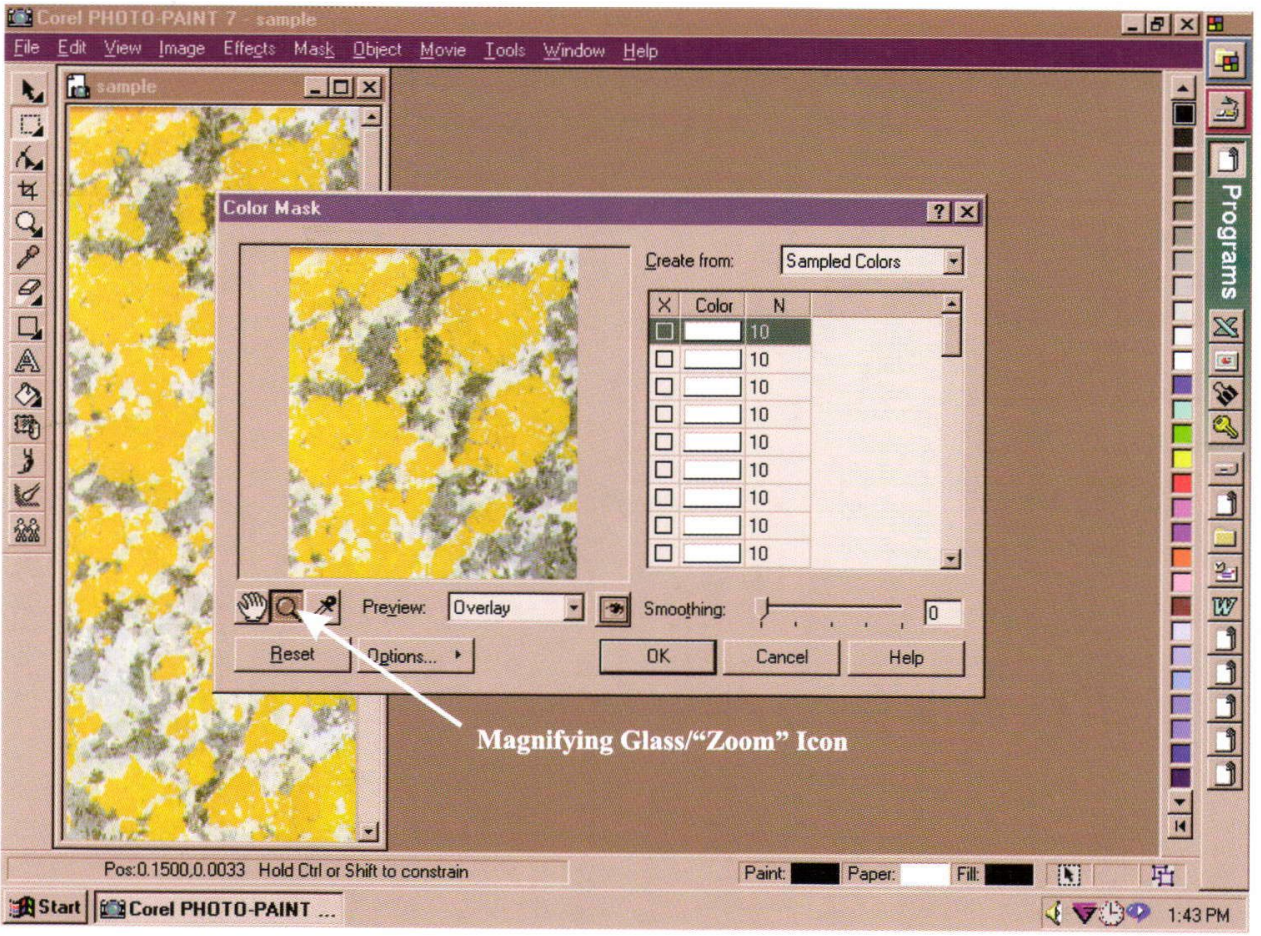

Fig. 2. A view of the scanned sample and the colour mask window. The magnifying glass tool allows the user to "zoom in" on the sample area in the colour mask window for more accurate pixel colour selection. 


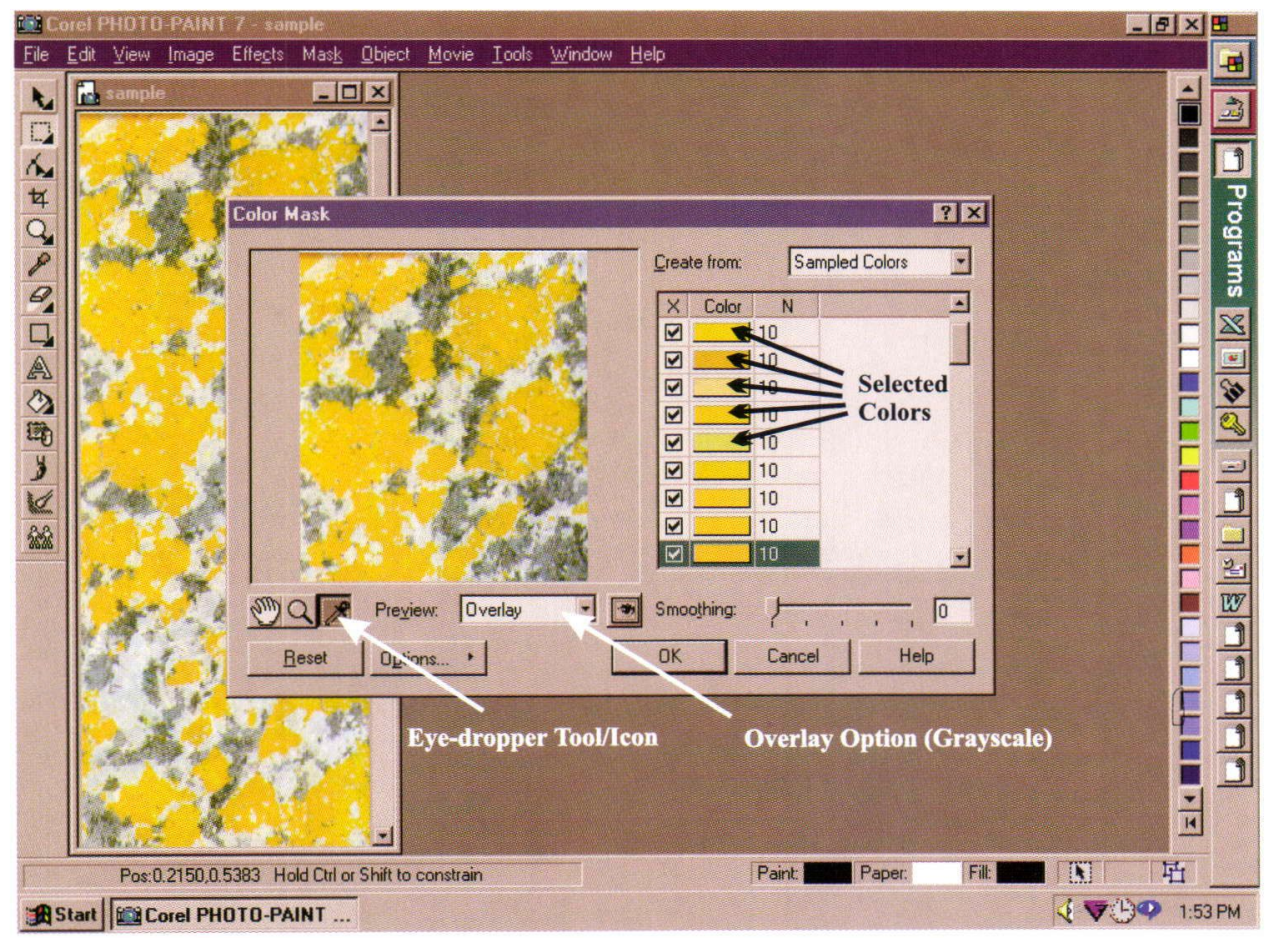

Fig. 3. The view of the colour mask window after colour shades have been selected with the eye dropper tool. The overlay option: greyscale reduces the image into two colours, representing the colour mask colours (white) and the rest of the rock (black).

\section{Step \#4:}

From the "Mask" menu choose "Paint On Mask" $(\mathrm{Ctrl}+\mathrm{K})$, and the image will be displayed as a binary image, white representing the total area of the selected mineral, and black representing the remainder of the rock (Fig. 4).

\section{Step\#5:}

Choose "Histogram" from the "Image" menu, and select the histogram range (i.e. colour range) in the histogram box (Fig. 5). In this case, the sample is represented by the entire histogram range ( 0 to 255 ), and the selected mineral (alkali feldspar) is represented by the colour white ( 255 in the histogram range). The exact percentage of the total area is displayed in the "Percent:" box; this is the percentage of the selected mineral for that rock sample (Fig. 6). The same process can be repeated for other mineral modes (i.e. plagiocla- se, quartz, and dark minerals), and the rock can then be classified according to the IUGS classification for plutonic rocks (Le Maitre 1989).

\section{DISCUSSION}

This method for determination of mineral modes in coarse-grained plutonic rocks appears to be considerably more accurate than traditional thin section point counting or manual point counting of stained samples via stereomicroscope (cf. Plafker 1956). Thin section point counting would be the preferable method of analysis, but it does not sufficiently account for the large grain size in coarsegrained rocks. Manual point counting is fairly accurate, but the procedure is very time consuming and may be considerably less accurate than analysing by colour masking digital images. For com- 


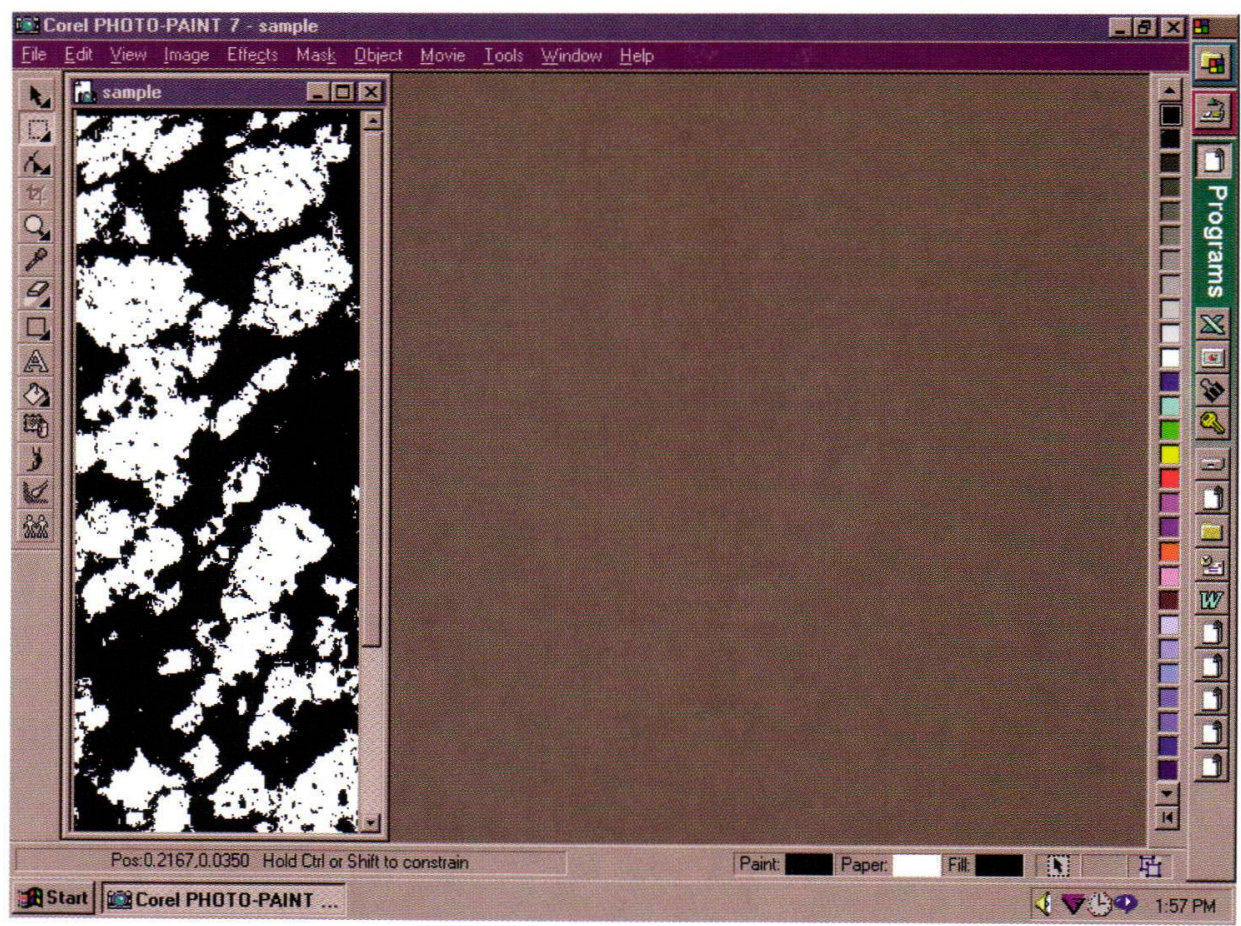

Fig. 4. The scanned image with the greyscale colour mask applied for the selected mineral mode, in this case alkali feldspar.

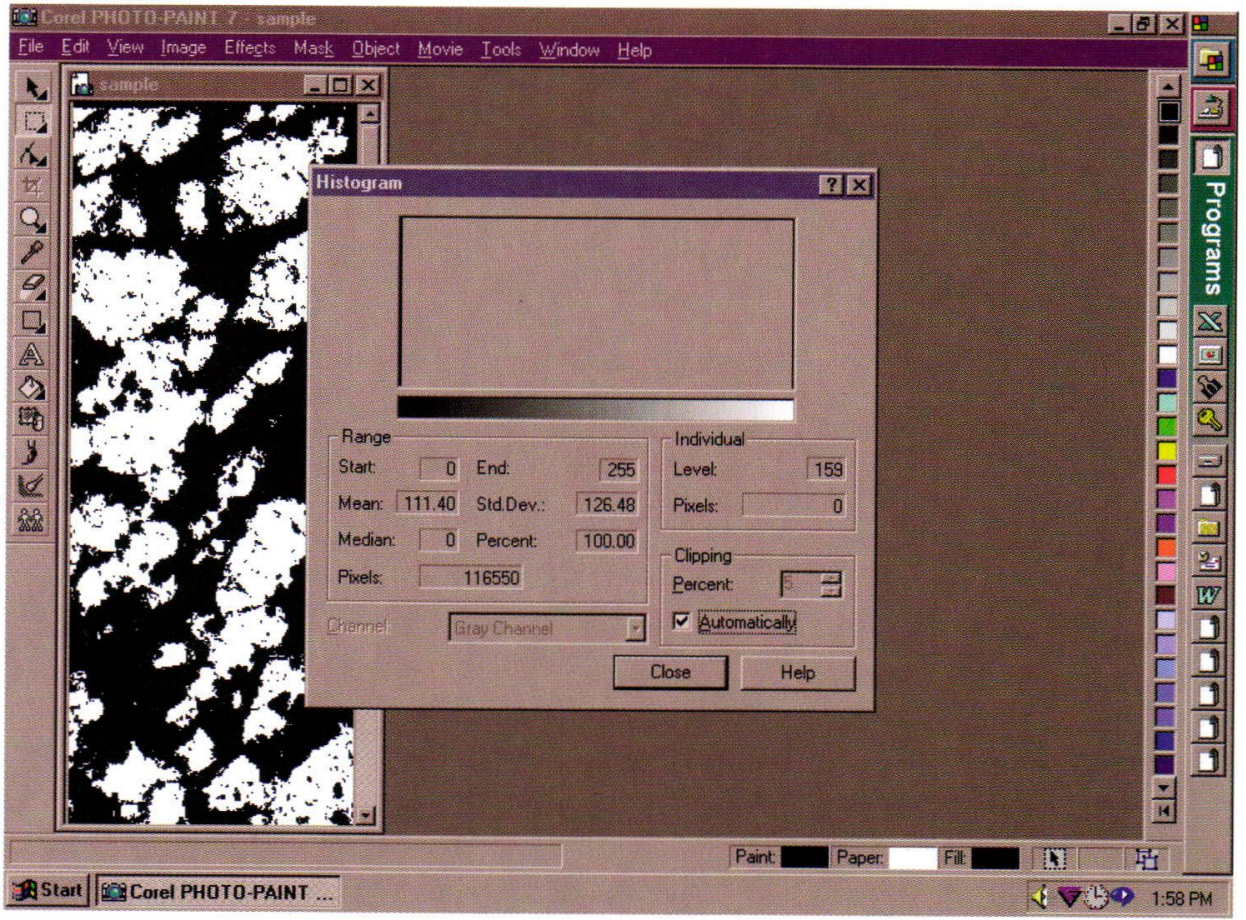

Fig. 5. A view of the histogram window, showing the total number of pixels and the pixel colour range and values in the image (background) with the greyscale colour mask applied. 


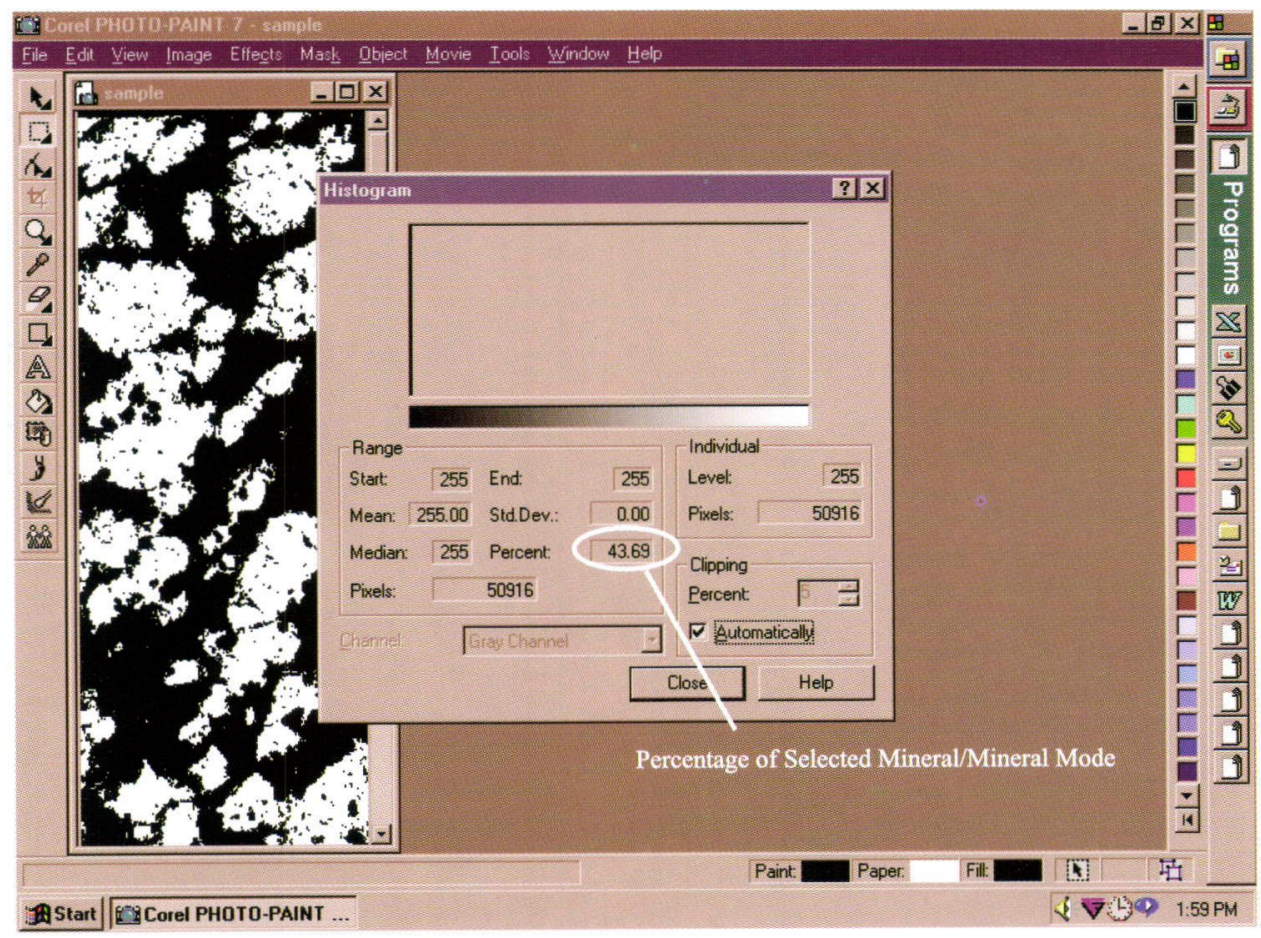

Fig. 6. A view of the histogram window showing the selected pixel colour range (white: 255 to 255), and the percentage of the total image area representing that colour, or mineral, as a function of the number of pixels [50916 divided by the total number of pixels 116550 (Fig. 5)].

parison, eight samples with variable grain size were point counted manually and by image analysis. The results of the comparative analysis are shown in Table 1 and Fig. 7. Samples were analysed ten times to quantitatively determine reproducibility and degree of error. The resulting classifications for the fine- and medium-grained rocks are generally similar. The classification of the coarse-grained rocks (samples 7 and 8 ) is considerably different between analysing methods. This is primarily due to the sample area, the manual point counting covered areas of $24 \mathrm{~cm}^{2}$, while the image analysis method covered an area of $60 \mathrm{~cm}^{2}$ and $100 \mathrm{~cm}^{2}$. The pixel resolution method allows for a larger stained area to be analysed, only restricted by the size of the scanner. The manual point counting method would have to comprise about 60000 and 100000 points, respectively, for a more accurate comparison, a truly time consuming process. The finer grained rocks were analysed on a comparable scale, with similar results. It ap- pears that the pixel resolution method is not restricted by grain size, but more accurate results, or a lesser degree of error, are obtained with coarser grained rocks.

Analytical problems may occur if very few colour shades are chosen for a colour mask. A lesser number of colour shades/tones will result in less accurate results, the total of mineral modes being far less than $100 \%$. Colour shade redundancy between different colour masks can cause analytical error. If colour selections are made carelessly, the mode calculations may be over $100 \%$, resulting in a large degree of error. The quality of staining can influence the accuracy of the mode determination. Poorly stained samples result in obscure light coloured stains that can cause redundancy in colour shades between different mineral modes.

Dark minerals cannot be distinguished from one another by this method. For example, biotite and amphibole may occur, but the mineral modes can- 
Table 1. Eight samples representing a range of grain size, analysed for modal compositions by manual point counting and image analysis methods. Standard deviation is given for ten analyses of each sample using the colour masking method.

\begin{tabular}{|c|c|c|c|c|c|c|c|c|}
\hline Pixel Method & 1 & 2 & 3 & 4 & 5 & 6 & 7 & 8 \\
\hline Average grain size & $1.5 \mathrm{~mm}$ & $4 \mathrm{~mm}$ & $<1$ to $7 \mathrm{~mm}$ & $<1$ to $5.5 \mathrm{~mm}$ & $5 \mathrm{~mm}$ & $2 \mathrm{~mm}$ & $14 \mathrm{~mm}$ & $12 \mathrm{~mm}$ \\
\hline Analysis Area & $35 \mathrm{~cm}^{2}$ & $45 \mathrm{~cm}^{2}$ & $40 \mathrm{~cm}^{2}$ & $42 \mathrm{~cm}^{2}$ & $56 \mathrm{~cm}^{2}$ & $49 \mathrm{~cm}^{2}$ & $100 \mathrm{~cm}^{2}$ & $60 \mathrm{~cm}^{2}$ \\
\hline Area (pixels/points) & 62160 & 66960 & 97371 & 97371 & 122250 & 89100 & 231775 & 97440 \\
\hline Alkali Feldspar & $59.32 \pm 1.52$ & $50.35 \pm 0.94$ & $58.81 \pm 1.16$ & $40.39 \pm 1.88$ & $50.05 \pm 1.55$ & $49.02 \pm 1.53$ & $39.93 \pm 0.71$ & $39.20 \pm 0.34$ \\
\hline Plagioclase & $5.32 \pm 0.69$ & $4.79 \pm 0.48$ & $5.71 \pm 0.48$ & $7.28 \pm 0.55$ & $7.63 \pm 0.54$ & $10.59 \pm 0.95$ & $16.55 \pm 0.51$ & $25.98 \pm 0.38$ \\
\hline Quartz & $20.20 \pm 1.74$ & $33.04 \pm 0.87$ & $30.57 \pm 1.18$ & $36.57 \pm 0.83$ & $34.17 \pm 0.88$ & $32.67 \pm 0.98$ & $39.95 \pm 0.52$ & $30.88 \pm 0.66$ \\
\hline Mafic Minerals & $4.93 \pm 0.83$ & $6.04 \pm 0.51$ & $5.80 \pm 0.53$ & $3.07 \pm 0.66$ & $4.62 \pm 1.00$ & $5.12 \pm 1.12$ & $2.63 \pm 0.23$ & $2.67 \pm 0.34$ \\
\hline Total & $89.78 \pm 2.73$ & $94.22 \pm 2.80$ & $100.90 \pm 3.35$ & $87.32 \pm 3.91$ & $96.48 \pm 3.97$ & $97.39 \pm 4.59$ & $99.05 \pm 1.97$ & $98.74 \pm 1.72$ \\
\hline Manual Method & 1 & 2 & 3 & 4 & 5 & 6 & 7 & 8 \\
\hline Average grain size & $1.5 \mathrm{~mm}$ & $4 \mathrm{~mm}$ & $<1$ to $7 \mathrm{~mm}$ & $<1$ to $5.5 \mathrm{~mm}$ & $5 \mathrm{~mm}$ & $2 \mathrm{~mm}$ & $14 \mathrm{~mm}$ & $12 \mathrm{~mm}$ \\
\hline Analysis Area & $16 \mathrm{~cm}^{2}$ & $16 \mathrm{~cm}^{2}$ & $16 \mathrm{~cm}^{2}$ & $16 \mathrm{~cm}^{2}$ & $16 \mathrm{~cm}^{2}$ & $16 \mathrm{~cm}^{2}$ & $24 \mathrm{~cm}^{2}$ & $24 \mathrm{~cm}^{2}$ \\
\hline Area (pixels/points) & 1600 & 1600 & 1600 & 1589 & 1600 & 1600 & 2400 & 2400 \\
\hline Alkali Feldspar & 55.50 & 50.90 & 59.10 & 43.10 & 49.10 & 46.70 & 51.41 & 56.59 \\
\hline Plagioclase & 6.38 & 5.90 & 6.90 & 10.40 & 9.20 & 14.20 & 12.42 & 24.79 \\
\hline Quartz & 33.43 & 37.50 & 30.40 & 44.05 & 37.30 & 34.40 & 29.71 & 13.46 \\
\hline Mafic Minerals & 4.69 & 5.70 & 3.60 & 2.45 & 4.40 & 4.70 & 6.46 & 5.16 \\
\hline Total & 100.00 & 100.00 & 100.00 & 100.00 & 100.00 & 100.00 & 100.00 & 100.00 \\
\hline
\end{tabular}




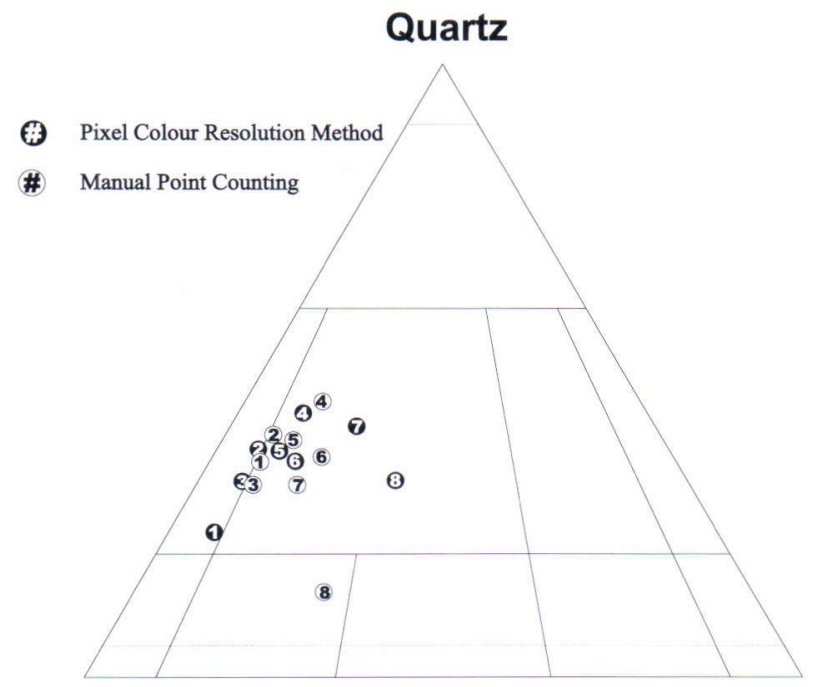

\section{Alkali Feldspar}

\section{Plagioclase}

Fig. 7. IUGS classification of quartz saturated plutonic rocks; numbered open circles represent the samples analysed by manual point counting, and closed circles represent the same numbered samples analysed by the pixel resolution method.

not be calculated other than a percentage of dark minerals of the total area. Similarly, accessory mineral modes for minerals such as zircon and apatite cannot be determined due to size, abundance, and lack of colour resolution.

\section{CONCLUSIONS}

The determination of mineral modes by colour masking digital images is an efficient, quick, and accurate method to calculate modal compositions for K-feldspar, plagioclase, quartz and dark minerals in coarse-grained plutonic rocks. The process is considerably faster and more accurate than traditional methods of analysing coarse-grained granitic rocks by manual point counting or thin section point counting. This method should not be limited to coarse-grained plutonic rocks, and can be used to estimate mineral modes in finer grained rocks and stained thin sections. Although thin section point counting can be more accurate in determining mineral compositions and accessory minerals, and distinguishing between different mafic silicate and opaque minerals, it may result in incorrect modal compositions for coarser grained rocks.

ACKNOWLEDGEMENTS. The sample analyses by manual point counting for the fine- to mediumgrained rocks (samples 1 to 6) were stained and analysed by Sari Lukkari, who graciously allowed the data to be used for comparison. This paper benefited from many useful discussions with Stephen Frindt, Paula Kosunen, and Tapani Rämö pertaining to the quantitative and qualitative aspects of the pixel resolution method. Special thanks to Stephen Frindt for assisting with the sample cutting and Paula Kosunen for assistance in the sample staining. Constructive comments from Yrjö Kähkönen, Jukka Laukkanen, and Kari Kojonen were greatly appreciated.

\section{REFERENCES}

Bailey, E.H. \& Stevens, R.E. 1960. Selective staining of $\mathrm{K}$-feldspar and plagioclase on rock slabs and thin sections. American Mineralogist 45, 1020-1025. 
Chayes, F. 1952. Notes on the staining of potash feldspar with sodium cobaltinitrite in thin section. American Mineralogist 37, 337-340.

Gabriel, A. \& Cox, E.P. 1929. A staining method of quantitative determination of certain rock minerals. American Mineralogist 14, 290-292.

Hayes, J.R. \& Klugman, M.A. 1959. Feldspar staining methods. Journal of Sedimentary Petrology 29, 227-232.

Jackson, E.D. \& Ross, D.C. 1956. A technique for modal analyses of medium- and coarse-grained (3-10 mm) rocks. American Mineralogist 41, 648-651.

Keith, M.L. 1939. Selective staining to facilitate Rosiwal analysis. American Mineralogist 24, 561-565.

Le Maitre, R.W. (ed.) 1989. A Classification of Igneous
Rocks and Glossary of Terms - Recommendations of the International Union of Geological Sciences Subcommision on the Systematics of Igneous Rocks. Oxford: Blackwell. 193 p.

Nironen, M., Elliott, B.A. \& Rämö, O.T. in print. 1.881.87 Ga post-kinematic intrusions of the Central Finland Granitoid Complex: a shift from C-type to A-type magmatism during lithospheric convergence. Lithos.

Nold, J.L. \& Erickson, K.P. 1967. Changes in K-feldspar staining methods and adaptations for field use. American Mineralogist 52, 1575-1576.

Plafker, G. 1956. A technique for modal analyses of some fine- and medium-grained $(0.1-5 \mathrm{~mm})$ rocks. American Mineralogist 41, 652-655. 